\title{
COLONIAL DEVELOPMENT AND RESEARCH
}

W

HEN on February 20 the House of Commons turned for a brief space from its preoccupation with the War to listen to Mr. Malcolm MacDonald, H.M. Secretary of State for the Colonies, as he announced the decision of the Government in the matter of the report of the West India Royal Commission, 1938-39, it must have been a source of both pride and gratification to the members that, at a time when every resource is strained in the effort to preserve all for which our society and system of government stand, the loyalty and support which the mother country has received from her colonial dependencies should be met by a no less striking manifestation of solicitude on the part of Great Britain for their inhabitants. As already pointed out (see Nature, March 2, p. 342), the statement of future policy in relation to the development and welfare of the colonies then made by Mr. MacDonald* not only marks a new departure in the relations, financial and other, of the central and local administrations, but it also extends vastly the ficld in which the sense of responsibility of the mother country for the wellbeing of the inhabitants of these territories will be enabled to find effective expression. This interrelation is well defined in the words of the statement itself, that His Majesty's Government, regarding themselves as "trustees for the well-being of the peoples of the Colonial Empire", look upon "the spontaneous and wholehearted support given by the inhabitants of every territory to the common war effort as the best testimony to their appreciation of the way in which that trust is being discharged" ; while on the other hand, it is said, "the primary aim of Colonial policy is to protect and advance the interests of the inhabitants of the Colonies (in which term are included . . . Protectorates and Mandated Territories)".

Mr. MacDonald's announcement is the outcome of no hasty and improvised decision. Indeed, it is stated that this further development of Colonial policy was settled in principle some time ago, and final decisions were postponed only pending the result of the West India inquiry. It has been evident for a considerable period that circumstances, aggravated by the economic depression, not only militated against the social and economic well-

* Statement of Policy on Colonial Development and Welfare. (Cmd. 6175.) Pp. 8. (London: H.M. Stationery Office, 1940.) 2d. net. being of the inhabitants of, for example, the African dependencies under the Colonial Office, but also were rapidly approaching a stage at which drastic remedial measures, beyond the resources of the local administration, would have to be applied. It is now pointed out that while much has already been accomplished, there is room for further active development of the natural resources of the various territories so as to provide their peoples with improved standards of life.

The conclusion at which the Government has arrived, after consideration of the efiect of such limited resources derived from agriculture as are available in most of the dependencies, in relation to a policy of steady development, is that many colonies cannot finance out of their own resources the research and survey work, the schemes of major capital enterprise, and the expansion of administrative and technical staffs, which are necessary for their full and vigorous development. The old principle that a colony should have only those services which it can afford to maintain out of its own resources is to go by the board, and in future, assistance will be given not merely for capital expenditure or material development-in the main the objects of the Colonial Development Fund instituted in 1929but also the money from new sources now to be provided is to be made available for the maintenance of important works or services over a substantial period of years.

For the sake of clearness, it may not be out of place here to recapitulate briefly the financial arrangements now proposed, and the machinery to be instituted for their employment.

The Colonial Development Fund, instituted in 1929 and limited to a maximum of $£ 1,000,000$ a year, will be replaced by a new vote in the estimates for assistance to Colonial Governments up to a maximum of $\mathfrak{£ 5 , 0 0 0 , 0 0 0}$ a year for ten years. This assistance will be available not only for schemes involving capital expenditure for colonial development, but also for helping to meet recurrent expenditure on certain services, such as agriculture, education, health and housing.

Bearing in mind the proposals for research made by Lord Hailey in his "African Survey", the Government proposes to make special provision for research. Hitherto, expenditure on various 
forms of Colonial research has received assistance from the Colonial Development Fund. In future, for this purpose a separate sum will be allocated up to a maximum amount of $£ 500,000$ a year.

As regards the manner of allocating expenditure from these funds, the Government will enlist the help of a Colonial Development and Welfare Advisory Committee, which will be composed partly of official and partly of unofficial members.

In the province of research, in the past the authorities have had recourse in dealing with questions of Colonial research to the advice of scientific and technical experts in Great Britain; but they are now anxious to place the system on a wider and more regular basis. It is considered that this object can be best achieved by the establishment of a Colonial Research Advisory Committee. It is not anticipated that the full scale of expenditure will be reached all at once, especially in present conditions; but so far as possible, steps will be taken immediately to give these proposals effect.

It will be seen that this extension of policy in colonial development represents a very appreciable step in advance. Its most marked effects should be immediately apparent in the removal of the restrictions which virtually, if not in terms, confined previous grants-in-aid to non-recurrent capital expenditure and material development. In no departments of colonial administration have efforts at amelioration been so cramped as in the provision for health services and education-both of paramount importance in raising the standard of well-being among the native populations. By a prolonged course of education alone can the object of the health services really be fully attained.

It is natural that in this much enlarged policy of colonial development the first emphasis should be laid on the improvement of the economic position of the Colonies. Although in any consideration of the amelioration of colonial conditions it has come to be almost a matter of course to consider how and in what way the native population is affected, the interests of the white settler are not to be overlooked. On his shoulders in most instances rests the main burden of the development of the natural resources of the territory ; and anything which contributes to promoting the improvement of economic conditions must be to his advantage as well as a further stage in progress towards self-sufficiency.

At the same time, even in such conditions, as always, the foundation of the social and economic structure is the native population. It is this consideration which weighs the argument when it is urged that whatever delay may be imposed on development by current conditions and the claims of the vigorous prosecution of the War, some part at least, and that the more urgent, of the expenditure on research may be pressed forward as a first. and immediate charge. Among subjects of inquiry, a plea must be put forward for intensive study of the forms and constitution of native society. That the claims of this line of investigation should be stressed at this late date may seem a work of supererogation. Yet it is a question whether even yet the essential need of intensive study of native institutions and beliefs, and the implications of its conclusions, have been fully recognized, even though anthropologists have been attached officially to recent survey work, such as the nutritional survey in Rhodesia ; indirect rule itself, prior to its application, requires an investigation of the character of native institutions before it is possible to make use of them in the administration of native affairs. Recent investigations in West Africa, for example, suggest that indirect rule, where it is now in being, may sometimes rest on an uncertain foundation, notwithstanding preliminary inquiry, when dealing with so complex a matter as the seat of authority in an African community. The farther and deeper goes research in the social anthropology of African peoples, the more patent becomes the closely woven nexus of social and religious or quasi-religious relations of the com. munity. It is impossible to touch the part without affecting the whole.

The significance of further and intensive research in social anthropology as a priority condition of the application of measures of colonial development affecting the native should be obvious. There is no measure of amelioration, whether it be in health, nutrition, agriculture, land tenure, education, housing, or social reform generally, which does not necessarily impinge upon, and to some extent modify, some sides of native life. What those sides are, how extensive their ramifications, and to what extent they may introduce further and unanticipated changes in mode of life, to the disadvantage of the community, the anthropologist is better able than anyone else to say. Many mistakes, reacting to the disadvantage of the native population, have been made in the past in default of such expert guidance. The delay which must supervene in the full application of the new policy of development at least gives opportunity for their avoidance from this cause in the future. 